\title{
OPERATIONAL RELIABILITY OF FIRE APPLIANCES ON MERCEDES-BENZ CHASSIS WITH BRIGADES OF FIRE RESCUE SERVICE OF THE MORAVIAN-SILESIAN REGION
}

This paper is focused on the evaluation of data obtained from operational records of fire appliances for the period 2010 - 2013 with emphasis on fire appliances built on Mercedes-Benz chassis. These vehicles are operated by the professional units of Fire Rescue Service of the Moravian-Silesian Region. The data recorded in electronic form in operational records were analysed. The primary result of this analysis was the selection of repairs after failure. Failure severity with regard to the functional reliability of fire appliances was used as selection criterion. Subsequently the assessment of the reliability was performed by setting selected characteristics from a group of complex reliability indicators.

Keywords: Operational reliability, fire appliance, service, failure, repair.

\section{Introduction}

Detailed calculation results of selected reliability characteristics for fire fighting vehicles built on Mercedes-Benz (MB) chassis are presented in this paper. The results emerged from the evaluation of primary data on the operation of these vehicles. This paper follows the previous publication which evaluates the operation and maintenance of MB chassis fire fighting vehicles [1]; it also extends previous researches in this area conducted in 2010 [2] by adding vehicles built on Econic chassis to the observed group. The results of the analysis of operational characteristics will not be discussed in detail hereafter, but the final selected values will be given only for providing an overview of vehicle utilization.

\section{Characteristics of observed fire fighting vehicles}

The Moravian-Silesian Region, which has an area of 5.4 thousand $\mathrm{km}^{2}$ and a population of about 1.2 million, is in terms of organization of fire brigades divided into 6 regional departments, with a total of 22 fire stations. Seven fire fighting vehicles on MB Econic chassis are placed at six fire stations in the regional department of Ostrava. Eleven fire fighting vehicles on MB Atego chassis are located at the regional departments outside of Ostrava. The MB Atego vehicles represent the standard intervention vehicles, namely first and second response vehicles; crew size of 6, 25001 water tank, middle weight category with mixed chassis
$4 \times 4$ suitable for unpaved roads [3 and 4]. MB Econic vehicles represent the exclusively urban intervention fire fighting vehicles; crew size of 6,27001 water tank, chassis $4 \times 2$, heavy weight category [4].

The MB Atego vehicles had the average annual mileage of $4864 \mathrm{~km}$, the MB Econic vehicles were comparable with $4352 \mathrm{~km}$. The share of machine work in place in motohours was $50 \%$ on an average for the MB Atego vehicles, whereas for the MB Econic vehicles, it was only $28 \%$ on an average. When comparing the response activity with other activities, the difference is bigger. In the case of the MB Atego vehicles, response actions form $64 \%$ in comparison with the MB Econic vehicles with $70 \%$. The absolute numbers of repairs per vehicle regardless of failure severity per four years of observation were on an average 14 failures per MB Atego vehicle and up to 20 failures on MB Econic vehicle [1].

As the observed vehicles have different chassis bases, each chassis class will be evaluated separately in the following text. The age of the vehicle is the second most important criterion that is used for the division of vehicles in calculations while assessing reliability. According to this criterion, the MB Atego vehicles are divided into two groups:

- vehicles under 10 years of age - 7 vehicles; the average age is 7.1 years,

- vehicles over 10 years of age - 4 vehicles; the average age is 10.3 years.

The MB Econic vehicles were not divided into the age groups; they are new vehicles that were put into service between 2010 and 2013.

\footnotetext{
* Ladislav Janosik, Marek Cochlar, Pavel Polednak

Department of Fire Protection, Faculty of Safety Engineering, VSB - Technical University of Ostrava, Ostrava-Vyskovice, Czech Republic

E-mail: ladislav.janosik@vsb.cz
} 


\section{Partial indicators of reliability characteristics}

Statistical data on maintenance and repairs [4] were provided to evaluate the failure rate of the observed vehicles. The data were divided into three groups, repairs after a failure (both on the chassis base and on the fire bodywork), preventive maintenance (inspection, testing, scheduled inspections, state technical inspections, emissions) and repair after damage (during the intervention, after a traffic accident). The results of analyses of operating characteristics in absolute values were published in [1]. Assessment of failure severity preceded the calculations of reliability characteristics. Criteria according to the FMEA method [3] were used for this. Insignificant failures were excluded from the group of failures. Results of calculations of selected reliability indicators following from the analysis of repairs after the failure will be presented in the following text. They are as follows:

- reliability,

- availability,

- mean time between failures,

- failure rate.

\section{Methods and results}

Reliability can be generally characterized as a property of the object consisting in the ability to perform required functions under defined conditions in a defined time period [5]. The so-called test plan method [6] was chosen for failure flow analysis [7 and 8] to evaluate this indicator. By this method, mean times to failure can be determined for a small group of products. The test plan censored by time-to-failure, so called " $t$ - plan", was used for failure rate evaluation. The duration of the test is the limit and the number of detected failures is a random variable. The assumption of the test is that the products are repaired after a failure. The accumulated working time of the vehicle $T_{A K U}$ is a time variable representing the course of the test. $T_{A K U}$ is the total time during which all products were in operation. The accumulated working time for the chosen $t$ - plan is calculated according to the following equation:

$T_{A K U}=\sum\left(\tau-\sum \theta\right)+(n-r) \cdot \tau_{0}$

where:

$\tau_{0}$ test time, from the beginning to the $r_{0}$-th failure,

$n$ number of tested products,

$r$ number of fault units,

$\theta_{i}$ time needed to repair the $i$-th product during the test interval.

The calculation of the accumulated working time according to equation (1) was conducted for four values of the test time: 20, 40, 60 and 80 hours. These intervals, after calculating by the average speed of $50 \mathrm{~km} / \mathrm{h}$, represent the mileages of 1000,2000 , 3000 and $4000 \mathrm{~km}$. In standard practice, indicators related only to the $1000 \mathrm{~km}$ mileage interval are used. The decision to use four intervals was based on operating vehicle loads stated in vehicle characteristics. The reason for this decision was to cover a longer time period of use of response fire appliances. The results of the calculations of accumulated operating time on an average per vehicle, both in hours and in kilometres, are provided in Table 1. The average speed of $50 \mathrm{~km} / \mathrm{h}$ was used for the calculation.

Results of accumulated working time calculations

Table 1

\begin{tabular}{|c|c|c|c|c|c|c|c|c|}
\hline $\mathbf{T}_{\text {AKU }}$ & \multicolumn{4}{|c|}{ MB Atego } & \multicolumn{4}{c|}{ MB Econic } \\
\hline$\tau_{0}[\mathrm{~h}]$ - test time & 20 & 40 & 60 & 80 & 20 & 40 & 60 & 80 \\
\hline$T_{A K U}$ per vehicle $[\mathrm{h}]$ & 19.2 & 38.7 & 57.4 & 76.0 & 19.7 & 37.1 & 49.2 & 62.1 \\
\hline$T_{A K U}$ per vehicle $[\mathrm{km}]$ & 959 & 1936 & 2868 & 3800 & 986 & 1855 & 2459 & 3105 \\
\hline
\end{tabular}

Mean Time Between Failures (MTBF) is the most frequently used indicator in practice for assessing the reliability of repairable systems. It is the mean operating time between two consecutive failures. The indicator is determined as the sample mean of the measured operating times according to [7 and 8]:

$T_{s}^{*}=\frac{1}{n} \sum_{i=l}^{n} t_{i}$

where:

$t_{i}$ the $i-t h$ vehicle operation time during the reporting period, $n$ the number of vehicles included in the test.

In the calculation, all monitored vehicles are included, i.e. both vehicles with failures and those without failures during the reporting period. The results of calculations for the observed vehicles are given in Table 2.

Results of "Mean Time Between Failures" Calculations

Table 2

\begin{tabular}{|l|c|c|c|c|c|c|c|c|}
\hline \multicolumn{1}{|c|}{ MTBF } & \multicolumn{4}{c|}{ MB Atego } & \multicolumn{4}{c|}{ MB Econic } \\
\hline$\tau_{0}[\mathrm{~h}]-$ test time & 20 & 40 & 60 & 80 & 20 & 40 & 60 & 80 \\
\hline$T_{s}{ }^{*}[\mathrm{~h}]$ & 15.5 & 28.9 & 39.7 & 46.9 & 19.7 & 37.1 & 49.2 & 62.1 \\
\hline$T_{s}{ }^{*}[\mathrm{~km}]$ & 777 & 1443 & 1984 & 2345 & 986 & 1855 & 2459 & 3105 \\
\hline
\end{tabular}

For the sake of completion, the distribution of the resulting values of $T_{s}^{*}$ at the division of MB Atego vehicles into the age groups is shown in Fig. 1. The expected fact that the interval between repairs shortens for vehicles over 10 years of age is confirmed here. This group of vehicles is approaching the decline stage in its life cycle. 


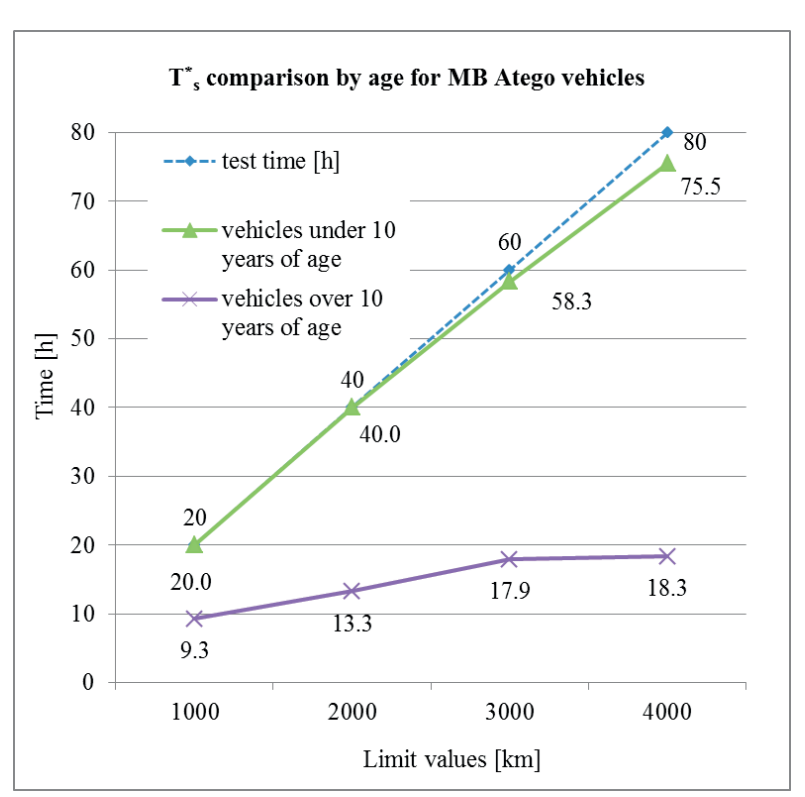

Fig. $1 T_{s}^{*}$ comparison by vehicle age

Failure rate depends on the life cycle stage of the technical system. In the normal use of the product, where the exponential law distribution of time-between-failures is valid approximately, it is possible to consider the $T_{s}^{*}$ value as constant [7 and 8]. This property was already tested in the previous study of the failure rate of MB Atego vehicles in 2006-2009 and is given in [2]. Then, the variable has a simple meaning, i.e. the average number of hours (or mileage in $\mathrm{km}$ ) per failure. Thus equation (3) is valid for calculating the failure rate $\lambda$ :

$\lambda=\frac{1}{T_{s}^{*}}$

The results of failure rate calculations for all vehicles regardless of age and separately for the two age groups of vehicles are given in Table 3 .

Failure rate of Mercedes-Benz vehicles

Table 3

\begin{tabular}{|c|c|c|c|c|c|c|c|c|}
\hline Failure rate & \multicolumn{4}{|c|}{ MB Atego } & \multicolumn{4}{c|}{ MB Econic } \\
\hline$\tau_{0}[\mathrm{~h}]$ - test time & 20 & 40 & 60 & 80 & 20 & 40 & 60 & 80 \\
\hline vehicles in total & 0.0644 & 0.0347 & 0.0252 & 0.0213 & 0.0507 & 0.0269 & 0.0203 & 0.0161 \\
\hline $\begin{array}{r}\text { vehicles under 10 } \\
\text { years of age }\end{array}$ & 0.0500 & 0.0250 & 0.0171 & 0.0133 & & & & \\
\cline { 1 - 4 } $\begin{array}{r}\text { vehicles over 10 years } \\
\text { of age }\end{array}$ & 0.1077 & 0.0754 & 0.0558 & 0.0545 & & & & \\
\hline
\end{tabular}

Availability is the ability of an object to perform the required functions under given conditions at a given time interval while ensuring the desired ambient conditions. This state of the object can be characterized by a number of complex indicators of reliability. Availability coefficient $K_{p}$ defined by equation (4) was used in our calculations at this stage of research [7]:

$K_{P}=\frac{\sum_{j=l}^{n} t_{p j}}{\sum_{j=l}^{n} t_{p j}+\sum_{i=l}^{n} t_{o i}}$

where:

$\sum t_{p j}$ the sum of times of failure-free operation,

$\sum t_{o i}$ the sum of service time during the period under review.

Calculation results for the defined periods of testing are shown in Fig. 2 where it can be seen that the assessment of fire appliances merely within one small interval of $1000 \mathrm{~km}$ is not the best predicative indicator.

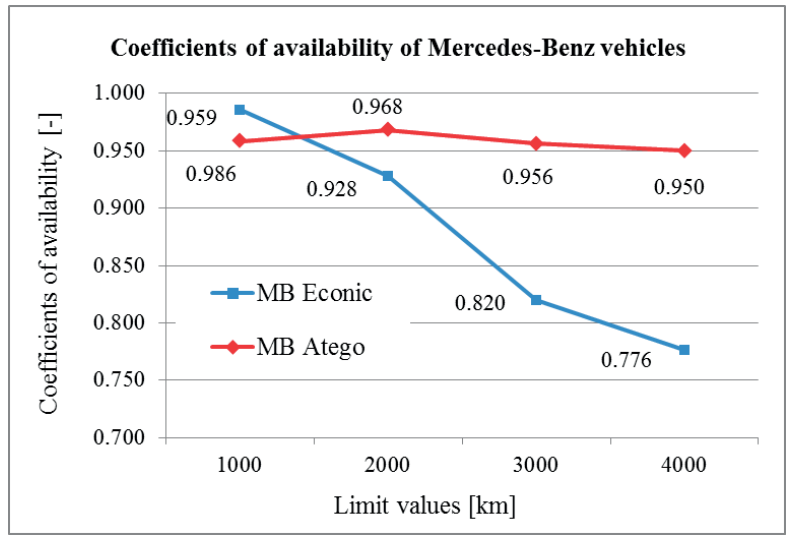

Fig. 2 Coefficient of availability of Mercedes-Benz vehicles

\section{Discussion}

The ongoing research is focused on the processing of data and the comparison of operation of fire appliances built on Mercedes-Benz, MAN, TATRA and Renault chassis. It is a case of a group of 75 vehicles located in the Moravian-Silesian, South Moravian and Zlin Regions.

The results may be distorted by the fact that the observed vehicles are not identical but only similar. The vehicles are in operation for various periods and have different workloads. First response vehicles, water tenders and backup vehicles are considered here. This fact should always be taken into account. It is necessary to observe vehicles in appropriately selected groups with similar characteristics.

Nevertheless, it is possible to form at least an approximate idea from the results of research by comparing the operation and the reliability of fire appliances built on different chassis. The comparison of appliances operating in urban agglomerations, such as Brno and Ostrava, will have other predictive value of results than the comparison of appliances in territories outside of these urban agglomerations. 
Achieving the ideal state of input data for the calculation of reliability of vehicles of the Fire Rescue Service of the Czech Republic seems to be, owing to the current composition of fire appliances from the point of view of models of individual vehicles and manufacturers of fire bodyworks, virtually impossible. Another factor affecting the results is the relatively rapid development both of chassis bases of fire fighting vehicles and especially of the design of fire bodyworks from the manual control of pump unit, through electro-pneumatic control up to the electronic systems of control in the fire bodywork via CAN (Controller Area Network) bus to control almost the entire vehicle, including the chassis base. These electronic control systems significantly influence the resulting functional reliability of the vehicle.

\section{Conclusion}

Summarized calculation results for the accumulated working time $T_{A K U}$ as characteristic of vehicle reliability are shown in Fig. 3 . TATRA vehicles in the South Moravian Region win in the results, while TATRA vehicles from the Zlin Region are at the other end of the results. The reason may be prosaic. The age of five vehicles in the observed group of 11 vehicles is 25 years. The MB Econic vehicles are at the very end of reliability. It should be noted here that the MB Econic vehicle is a development prototype, which is in the phase shortly after the startup stage on its lifecycle curve. More attention will be given to these vehicles in further research. Vehicles on MAN TGM chassis occupy together with MB Atego vehicles the imaginary second position. The mentioned vehicles have almost the same value of this parameter and their curves in the graph coincide. They differ only in the order of units of kilometres.

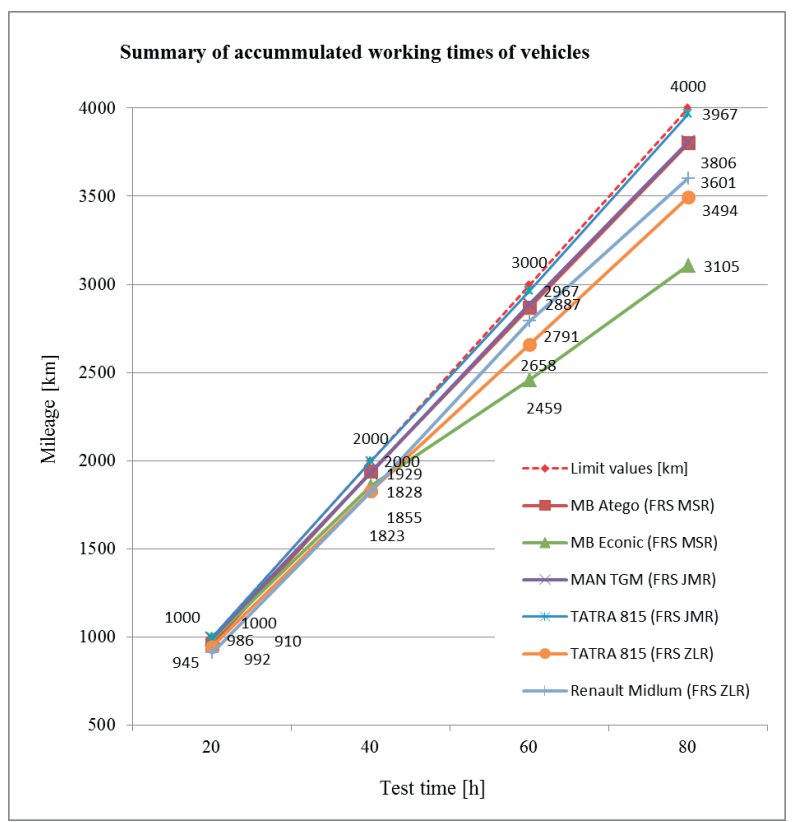

Fig. 3 Summarized results of accumulated working time calculation
The results of calculation of the reliability coefficient $K_{p}$ for all groups of monitored fire fighting vehicles are summarized in Fig. 4. The assumption made at the beginning of calculations that the time of $1000 \mathrm{~km}$ test is insufficient is confirmed here. The differences between the new MB Econic vehicles and the previously acquired appliances already begin to show themselves in the next interval $(2000 \mathrm{~km}=40 \mathrm{~h})$. These differences deepen in longer periods of observation.

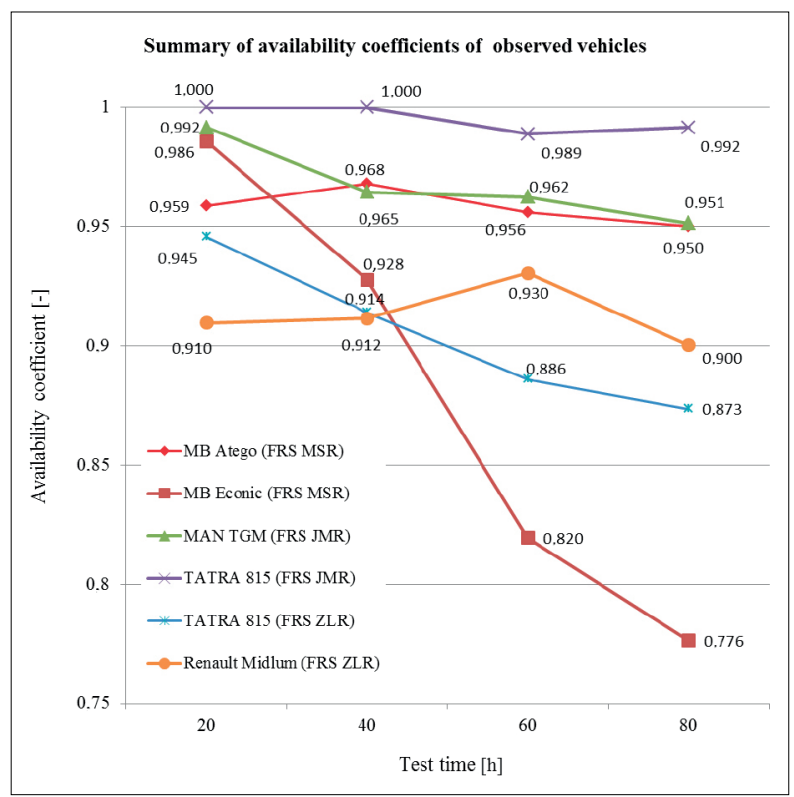

Fig. 4 Summarized results of availability coefficient calculation

The next stage of processing of operational data on observed vehicles is to calculate the partial indicators of maintainability and reparability of observed fire appliances and to complete this research.

\section{Acknowledgements}

This paper was supported by an internal grant of specific research "SP2014/44 - Determining aspects of operational and functional reliability of firefighting equipment.” 


\section{COMMNICOIIIONS}

\section{References}

[1] JANOSIK, L.: Evaluation of Fire Appliances on Mercedes-Benz Chassis with Brigades of Fire and Rescue Service of the MoravianSilesian Region (in Czech). Proc. of conference Riesenie krizovych situacii v specifickom prostredi, 21 - 22 May 2014, Zilina : University of Zilina, 2014, pp. 317-324, ISBN: 976-80-554-0875-0

[2] JANOSIK, L., PIKA, M., MONOSI, M.: Operational Reliability of Vehicles Mercedes-Benz Atego, Safety Engineering Series. Ostrava: VSB - Technical University of Ostrava, vol. V, No. 2, 2010, 122 p., ISSN 1801-1764. pp. 61-69.

[3] CSN EN 60812 - Analysis techniques for system reliability - Procedure for failure mode and effects analysis (FMEA) - in Czech). Praha: Czech office for Standards, Metrology and Testing, 2007, $37 \mathrm{p}$.

[4] MELECKY, P.: Personal Consultation and Operational Data Export from IKIS II (in Czech). Fire Rescue Servis of Moravian - Silesian Region, Regional Directorate Ostrava, Vyskovicka 40, 70030 Ostrava - Zabreh, January 2014.

[5] CSN IEC 50(191) - International electrotechnical vocabulary. Chapter 191: Dependability and quality of service (in Czech), Praha: Czech office for Standards, Metrology and Testing, 1993, 166 p.

[6] FAMFULIK, J., KRZYZANEK R., GALVAS, P.: Reliability Tests: Selected Stochastic Methods (in Czech) - $1^{\text {st }}$ ed., Ostrava : VSB Technical University of Ostrava, 2010, 67 p. ISBN 978-80-248-2277-8.

[7] STODOLA, J.: Operational Reliability and Diagnostics (in Slovak), Brno: University of Defence, 2002, 88 p.

[8] DANEK, A., SIROKY, J.: Theory of Replacement of Conveying Vehicles (in Czech), Ostrava: VSB - Technical University of Ostrava, 1999, 156 p. ISBN 80-7078-568-3. 